\title{
Application of a Portable Home Ventilator for Treating Flail Chest After Cardiopulmonary Resuscitation: A Case Report
}

\section{Dong Hyup Lee}

Yeungnam University Medical Center

Young Uk Lee ( $\nabla$ romio206@naver.com )

Yeungnam University Medical Center https://orcid.org/0000-0002-9593-4775

Tae-Eun Jung

Yeungnam University Medical Center

\section{Case report}

Keywords: Flail chest, Cardiopulmonary resuscitation, Portable ventilator

Posted Date: August 17th, 2021

DOI: https://doi.org/10.21203/rs.3.rs-731108/v1

License: (c) (i) This work is licensed under a Creative Commons Attribution 4.0 International License.

Read Full License 


\section{Abstract}

\section{Background}

Unexpected cardiopulmonary resuscitation and subsequent flail chest are rare in cardiac surgery patients. A patient with a flail chest frequently requires long-term mechanical ventilator care. Early application of portable home ventilator (PHV) might be a useful treatment.

\section{Case presentation}

A 61-year-old female who underwent cardiac surgery had unexpected cardiopulmonary resuscitation with a flail chest. For treating her flail chest, portable home ventilator was applied with several respiratory rehabilitations.

\section{Conclusion}

We think PHV is useful and alternative treatment for inappropriate for surgical fixation in flail chest patients.

\section{Background}

The incidence of unexpected cardiopulmonary resuscitation (CPR) after cardiac surgery is about 0.7$5.2 \%$. It has reduced in recent years [1-3]. Skeletal chest injury after CPR can occur at a rate of $90 \%$. The incidence of a flail chest after CPR is about $5 \%[4,5]$. A patient with a flail chest frequently patient requires long-term mechanical ventilator care. Application of a portable home ventilator (PHV) is one last major step when treating patients who require long-term mechanical ventilation. For patients with flail chest, early application of PHV is important. Here, we present a case of a patient with a flail chest successfully treated with PHV.

\section{Case Report}

A 61-year-old Asian female patient was referred to our department with dyspnea and palpitation. The patient had been diagnosed with mitral stenosis (MS) 20 years previously. She was on medication. Severe MS and mild tricuspid valve regurgitation were confirmed by echocardiography. Atrial fibrillation was also observed on electrocardiogram. Based on the above findings, the patient underwent mitral valve replacement, tricuspid valve annuloplasty, and mini-Maze. She was extubated and treated in a general ward. On the 12th postoperative day, the patient underwent pericardial window formation due to cardiac tamponade with large hematoma. Five days after the window operation, the patient had unexpected cardiac arrest and survived after 25 minutes of CPR. On the follow-up echocardiography, the replaced valve and cardiac function were normal. We attempted ventilator weaning and extubation twice. However, respiratory failure progressed due to a flail chest. 
Chest wall reconstruction computed tomography was then conducted to evaluate the flail chest and for surgical planning (Fig. 1A, 1B). Right 3rd-7th and left 2nd-7th anterior arch of rib fractures and displaced sternum were observed. However, it was difficult to determine the surgical fixation site because the flail segment was not prominent and the fracture displacement was not severe (Fig. 1C). Considering her nutritional state and previous two surgeries under general anesthesia, we decided to continue internal fixation with ventilator care.

Tracheostomy was performed on the 19th day after CPR. After about 2 weeks of ventilator weaning, PHV was applied (Fig. 2) and the patient started respiratory rehabilitation including intermittent positive pressure ventilation, coughing machine, and diaphragmatic respiration. The patient was transferred to a general ward at 3 weeks after PHV application. On transfer to the general ward, the following settings were used: synchronized intermittent mandatory ventilation mode, 02 flow rate at 2 liter/minute, respiration rate of 8 , and tidal volume of $350 \mathrm{ml}$.

PHV support and lung rehabilitation were continued for another three weeks. After chest wall stabilization and self-sputum toileting were confirmed, PHV weaning was done and the tracheostomy site was sealed off. Subsequently, the patient was discharged without any specific findings (Fig. 1D). She has been followed up at an outpatient clinic for three years. Currently, the patient activity is New York Heart Association classification I II without any specific problems.

\section{Disccussion And Conclusion}

Flail chest is caused by paradoxical movement of a flail segment caused by intrathoracic negative pressure. It can increase respiratory effort and cause atelectasis, eventually enhancing mortality and complication rates [6]. Management of flail chest includes maintenance of adequate ventilation, fluid and pain management, and stabilization of the chest wall. Typically, treatment of an unstable chest wall involves internal stabilization using a ventilator or surgical fixation of the flail segment [6]. Both methods have their advantages and disadvantages. Recent studies have reported that surgical treatment produces better results in terms of pneumonia incidence, intensive care unit (ICU) and hospital stays, lung function, and cost than the use of a ventilator [7-10]. However, surgical treatment has the disadvantage of exposing patients to surgical stress comparable to that caused by a traumatic event [9]. Furthermore, rib fractures after CPR tend to be underestimated by imaging, which can make it difficult to locate the prominent flail segment [7]. In addition, as seen in our case, general anesthesia and surgical treatment might be difficult for cardiac surgery patients due to hemodynamic instability, anticoagulant use, or previous sternotomy. In patients who have difficulties after surgical treatment, the use of PHV might be a good alternative. Home ventilators are relatively easy to operate and portable. They can be applied in general wards. Early hospital application of PHV and general ward transfer have both short-term and long-terms benefits. In a short term, PHV protects patients from severe ICU infections, reduces delirium, and facilitates treatment by increasing the range of rehabilitation treatments that can be applied. For patients requiring long-term ventilator care due to COPD, neuromuscular disease, skeletal disorder, or 
permanent damage to lung function due to trauma, in-hospital application of PHV can provide a useful adaptation period for patients and caregivers.

Recently, the use of noninvasive mechanical ventilation to avoid endotracheal intubation (ETI) has increased in the treatment of flail chest. Even if ETI and mechanical ventilation have been started, mechanical ventilation should be discontinued as soon as possible [11].

The importance of conservative treatment with rehabilitation and bedside treatment should not be overlooked. In the described case, respiratory rehabilitation was performed continuously, including intermittent positive pressure ventilation, coughing machine application, and diaphragmatic respiration. Bedside treatments such as manual percussion, encouraging ambulation, emotional support, and frequent respiratory toileting were also continuously performed or provided. Our patient was the first to receive PHV for flail chest at our hospital. To be cautious, we observed her adaptation in the ICU for about two weeks after applying PHV. In the future, the adaptation period of PHV can be shorter.

In summary, we report a case of a patient with a flail chest after CPR. Her flail chest was successfully treated with a PHV and respiratory rehabilitation without any surgical treatment. We think that PHV is useful as an alternative treatment for patients with a flail chest after surgical fixation.

\section{Abbreviations}

CPR

Cardio Pulmonary Resuscitation

PHV

Portable Home Ventilator

MS

Mitral Stenosis

ICU

Intensive Care Unit

ETI

Endo Tracheal Intubation

\section{Declarations}

\section{Ethics approval and consent to participate}

The case is resented anonymously, and patient consent have been obtained for publication

\section{Consent for publication}

Verbal informed consent was obtained from the patient for publishing this case report and accompanying images. 
Availability of data and materials

The dataset supporting the conclusions of this article is included within the article, and any other inquiry is available from the corresponding author on reasonable request

\section{Competing interests}

All authors declare that they have no competing interests relevant to this study.

\section{Funding}

This study received no funding.

\section{Authors' contribution}

YL wrote the draft of the manuscript and obtained the written and verbal consent. TJ and DL performed the surgery and literlature review and helped to the final writing of the paper. All authors have read and approved the final manuscript.

\section{Acknowledgement}

None

\section{References}

1. el-Banayosy A, Brehm C, Kizner L, Hartmann D, Körtke H, Körner MM, Minami K, Reichelt W, Körfer R. Cardiopulmonary resuscitation after cardiac surgery: a two-year study. J Cardiothorac Vasc Anesth. 1998 Aug;12(4):390-2.

2. Michaelis P, Leone RJ. Cardiac Arrest After Cardiac Surgery: An Evidence-Based Resuscitation Protocol. Crit Care Nurse. 2019 Feb;39(1):15-25.

3. Dunning J, Fabbri A, Kolh PH, Levine A, Lockowandt U, Mackay J, Pavie AJ, Strang T, Versteegh MI, Nashef SA, EACTS Clinical Guidelines Committee. Guideline for resuscitation in cardiac arrest after cardiac surgery. Eur J Cardiothorac Surg. 2009 Jul;36(1):3-28.

4. Enarson DA, Didier EP, Gracey DR. Flail chest as a complication of cardiopulmonary resuscitation. Heart Lung. 1977 Nov-Dec;6(6):1020-2.

5. Ananiadou O, Karaiskos T, Givissis P, Drossos G. Operative stabilization of skeletal chest injuries secondary to cardiopulmonary resuscitation in a cardiac surgical patient. Interact Cardiovasc Thorac Surg. 2010 Mar;10(3):478-80.

6. Perera TB, King KC. Flail C. 2021 Jan 20. In: StatPearls [Internet]. Treasure Island (FL): StatPearls Publishing; 2021 Jan-. PMID: 30475563.

7. Claydon O, Benamore R, Belcher E. Outcomes of chest wall fixation in cardiopulmonary resuscitationinduced flail chest. Interact Cardiovasc Thorac Surg. 2020 Sep 1;31(3):417-418. 
8. Schuurmans J, Goslings JC, Schepers T. Operative management versus non-operative management of rib fractures in flail chest injuries: a systematic review. Eur J Trauma Emerg Surg. 2017 Apr;43(2):163-8.

9. Nishiumi N, Fujimori S, Katoh N, Iwasaki M, Inokuchi S, Inoue H. Treatment with internal pneumatic stabilization for anterior flail chest. Tokai J Exp Clin Med. 2007 Dec;20(4):126-30. 32(.

10. Ahmed Z, Mohyuddin Z. Management of flail chest injury: internal fixation versus endotracheal intubation and ventilation. J Thorac Cardiovasc Surg. 1995 Dec;110(6):1676-80.

11. Schreiber A, Yıldırım F, Ferrari G, Antonelli A, Delis PB, Gündüz M, Karcz M, Papadakos P, Cosentini R, Dikmen Y, Esquinas AM. Non-Invasive Mechanical Ventilation in Critically III Trauma Patients: A Systematic Review. Turk J Anaesthesiol Reanim. 2018 Apr;46(2):88-95.

\section{Figures}

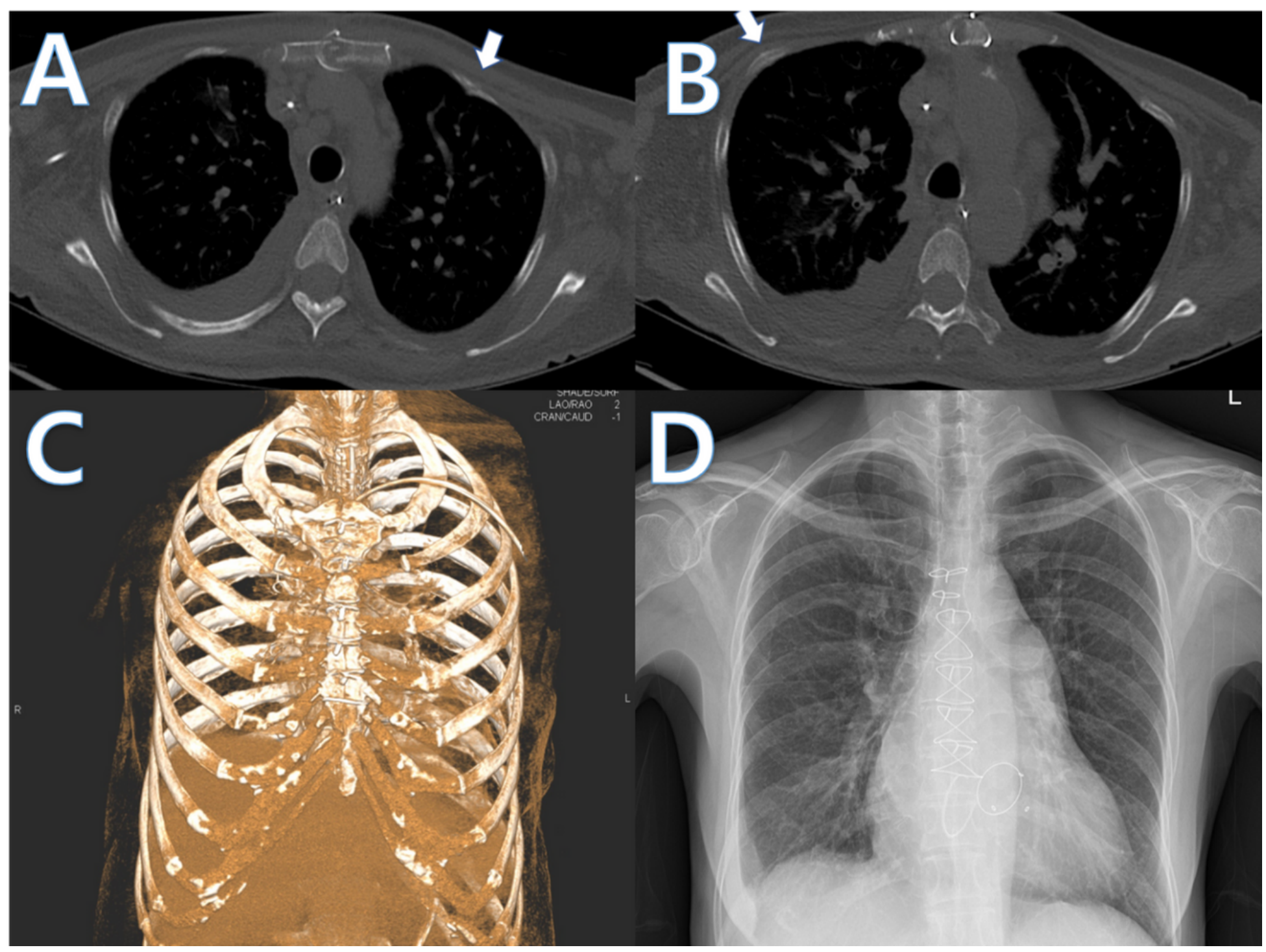

Figure 1 
A, B: Computed tomography findings for chest wall reconstruction. Image showing multiple rib fractures at the anterior arch and costochondral junction (white arrow). C: 3D Chest wall reconstruction. Flail segment was not prominent in 3D chest wall reconstruction. D: Chest $x$-ray at the time of discharge

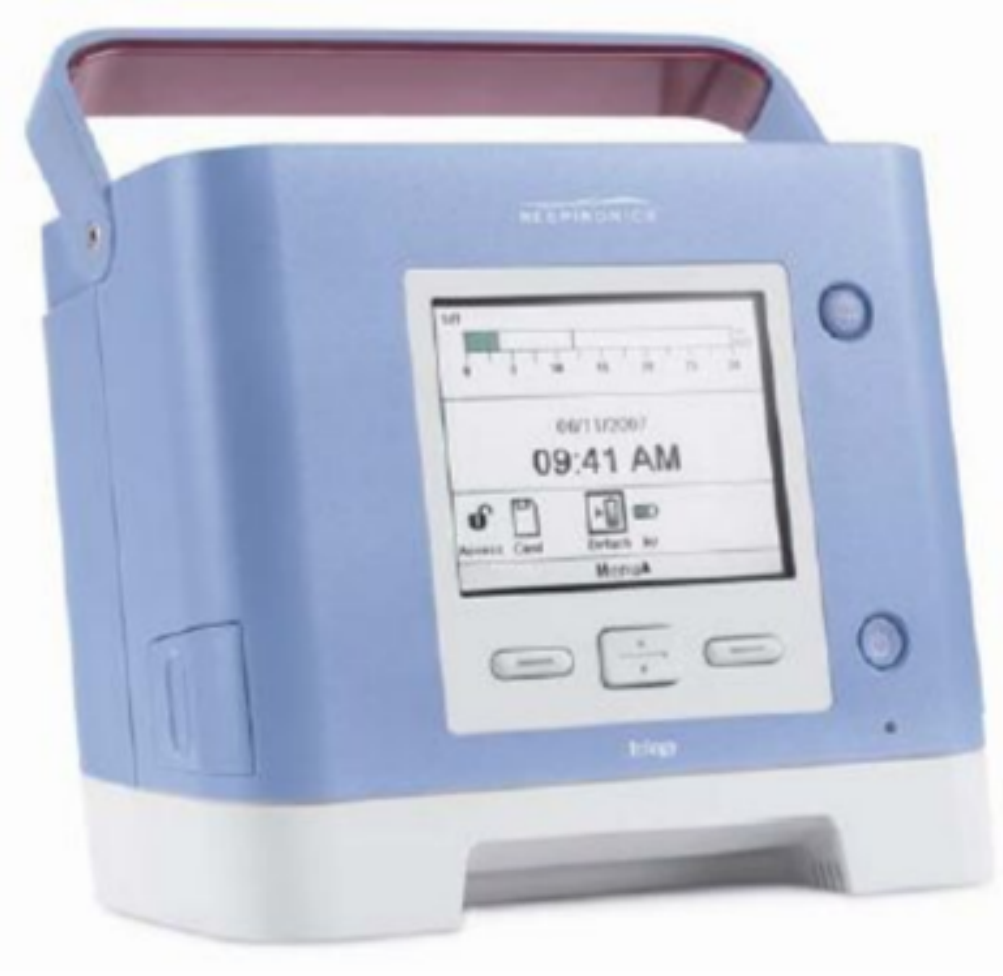

Figure 2

Portable home ventilator. Trilogy 100 (Philips Respironics: United States).

\section{Supplementary Files}

This is a list of supplementary files associated with this preprint. Click to download.

- CAREchecklist.pdf 